\title{
Role of dipstick in detection of haeme pigment due to rhabdomyolysis in victims of Bam earthquake
}

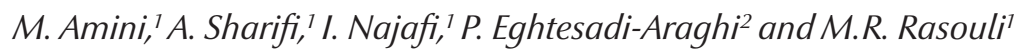

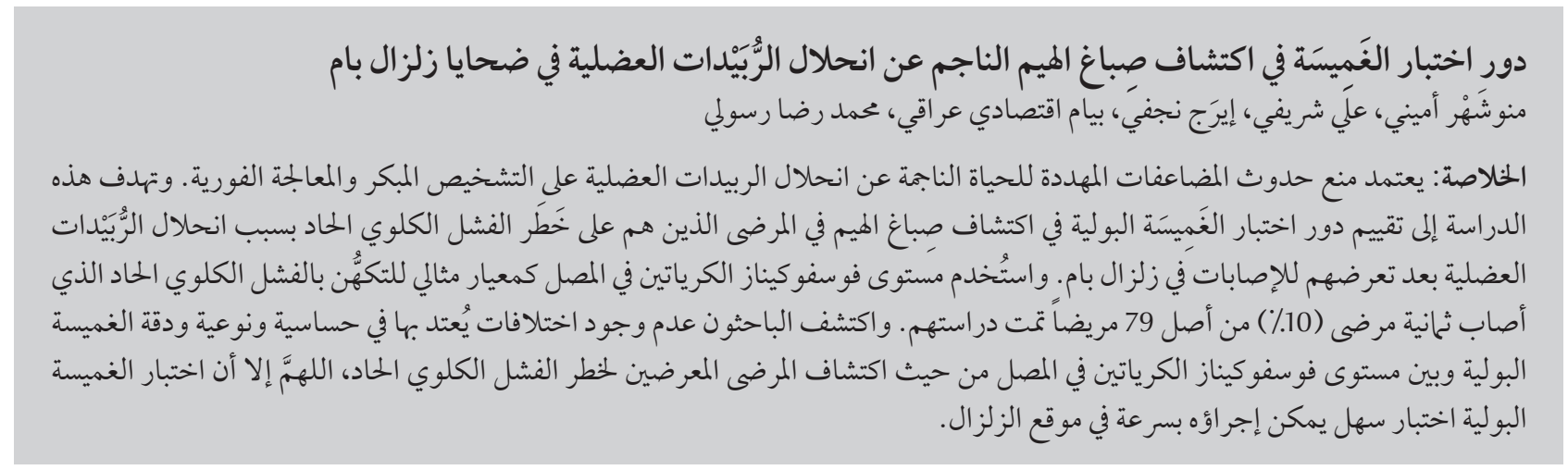

ABSTRACT Avoiding life-threatening complications of rhabdomyolysis depends on early diagnosis and prompt management. The aim of this study was to evaluate the role of urinary dipstick test in the detection of haeme pigment in patients who were at risk of acute renal failure (ARF) due to rhabdomyolysis after suffering injury in the Bam earthquake. Serum creatine phosphokinase (CPK) level was used as the gold standard for prediction of ARF. ARF developed in 8 (10\%) of 79 patients studied. We found no significant differences in the sensitivity, specificity and accuracy of dipstick urine and serum CPK tests for identifying patients who were at risk of ARF. However, dipstick urine test is an easy test that can be performed quickly at an earthquake site.

Rôle des bandelettes réactives dans la détection du pigment hémique lié à la rhabdomyolyse chez les victimes du tremblement de terre de Bam

RÉSUMÉ Un diagnostic précoce et une prise en charge rapide sont essentiels pour éviter les complications de la rhabdomyolyse mettant en jeu le pronostic vital. Cette étude visait à évaluer le rôle des bandelettes urinaires dans la détection du pigment hémique chez les patients présentant un risque d'insuffisance rénale aiguë lié à une rhabdomyolyse induite par une blessure lors du séisme survenu à Bam. Le taux de créatine-phosphokinase sérique (CPK) a été employé comme méthode de référence pour prévoir la survenue d'une insuffisance rénale aiguë. Huit des 79 patients étudiés (10\%) ont développé une insuffisance rénale aiguë. Nous n'avons relevé aucune différence significative en termes de sensibilité, spécificité et précision entre les bandelettes urinaires et les dosages de la CPK sérique dans l'identification des patients présentant un risque d'insuffisance rénale aiguë. Les bandelettes urinaires constituent cependant un test rapide et simple à réaliser sur les lieux d'un tremblement de terre.

'Department of Nephrology, Tehran University of Medical Sciences, Tehran, Islamic Republic of Iran.

${ }^{2}$ Parsteb Pajouheshyar Medical Sciences Research Institute, Tehran, Islamic Republic of Iran (Correspondence to P. Eghtesadi-Araghi: payam_ eghtesadi@yahoo.com).

Received: 02/02/09; accepted: 23/03/09 


\section{Introduction}

On 26 December 2003, an earthquake of amplitude 6.3 on the Richter scale hit the south-east of the Islamic Republic of Iran, decimating the city of Bam and killing more than 26000 people and injuring 30000 [1]. During catastrophic events such as earthquakes, crush syndrome is the second most frequent cause of mortality after the impact of trauma [2]. Crush injuries resulting in traumatic rhabdomyolysis are an important cause of acute renal failure (ARF) [3] in 4\%-33\% of patients, due to myoglobinuria [4]. This kind of ARF, requiring renal replacement therapy support, has a mortality rate of about $14 \%[5]$.

Avoiding life-threatening complications of rhabdomyolysis strongly depends on early diagnosis and prompt management of the condition [6]. Many clinical features of rhabdomyolysis are nonspecific, and the course of the syndrome depends on the underlying condition [7]. It has been demonstrated that the creatine phosphokinase (CPK) level in serum has an association with rhabdomyolysis [8]. However, it cannot be measured at the site of earthquake. It is therefore important to develop new easy screening tests.

Myoglobinuria establishes the diagnosis of rhabdomyolysis. Screening may be performed with a urine dipstick test [9]. The ortho-toluidine portion of the dipstick turns blue in the presence of haemoglobin or myoglobin. If a freshly-spun sediment of urine shows no red blood cells, positive urine blood can be used as a surrogate marker for myoglobin [7], although there is still the possibility of haemoglobinuria due to other causes such as intravascular haemolysis. Urine dipstick has been used for detection of rhabdomyolysis in patients suffering heat injury [10], physical abuse [11], general convulsions [12], immersion and near-drowning [13] and exercise-induced rhabdomyolysis [14]. To our knowledge it has not been not evaluated as a screening test in patients with rhabdomyolysis following injury in an earthquake.

This study evaluated the role of dipstick urinalysis in detection of haeme pigment in patients injured in the Bam earthquake who were at risk of ARF due to traumatic rhabdomyolysis. The study also compared the dipstick urinalysis as possible evidence of myoglobinuria with the serum CPK level which is considered to be the gold standard test in this setting. If sufficiently sensitive, urine dipstick analysis may provide a reliable screening test for rhabdomyolysis and could then be incorporated into future rapid screening protocols, thus allowing earlier initiation of treatment.

\section{Methods}

In a cross-sectional study, we evaluated all victims of the Bam earthquake who were admitted to the tertiary care centre of Shariati hospital, which is affiliated to Tehran University of Medical Sciences. Immediately after admission, a team including nephrologists and internists evaluated the patients for crush injury in the emergency department.

\section{Measured parameters}

In 79 patients admitted during the first 3 days after the earthquake, a urine dipstick test (Uriyab-8 tapes, Bakhtar Chimie) was performed using the first voiding or catheterization sample to detect haematuria/myoglobinuria. The reactions were evaluated visually by comparing the strip test areas with the colour chart printed on the bottle as either positive (from $1+$ to $4+$ ) or negative.

The first CPK value that had been measured during the first 3 days after the earthquake was obtained. Serum CPK level was estimated using a commercial kit (Pars Azmoon) and an autoanalyser (Technicon RA-1000).

\section{Criteria for ARF and haemodialysis}

ARF was defined as an acute loss of renal function with a persistent (at least 2 times on 2 different days) elevation of serum creatinine of $\geq 2.5 \mathrm{mg} / \mathrm{dL}$, which did not improve with hydration [15]. The criteria for haemodialysis were: serum creatinine $>8 \mathrm{mg} / \mathrm{dL}$, blood urea nitrogen $(\mathrm{BUN})>100 \mathrm{mg} / \mathrm{dL}$, serum potassium $>7 \mathrm{mEq} / \mathrm{L}$, serum bicarbonate $<10 \mathrm{mEq} / \mathrm{L}$, and clinical symptoms and findings of ARF such as oedema, hypertension, heart failure, nausea and vomiting [16].

\section{Statistical analysis}

Data were expressed as mean and standard deviation (SD) or number of patients. Statistical analysis ware performed utilizing SPSS, version 11.5 and MedCalc, version 9.2. Mann-Whitney $\mathrm{U}$ test was used to compare CPK levels in patients with and without ARF. The best cut-off points of urine dipstick and serum CPK level were obtained based on receiver operating characteristics (ROC) analysis and area under the curve (AUC). Then, comparison of AUCs was performed. Finally, sensitivity and specificity, positive predictive value, negative predictive value and accuracy of both tests for detection of occurrence of ARF were calculated. $P$ value $<0.05$ was considered statistically significant.

\section{Results}

A total of 79 patients including 54 males (68\%) were studied. The age distribution of the patients is shown in Table 1. Of these patients, 8 (10\%) developed ARF and 4 of them needed haemodialysis; 2 patients (2\%) died, 1 of them suffering ARF; 3 fasciotomies and 2 amputations were performed.

In Table 2, the results of urine dipstick are summarized. There was a significantly higher occurrence of positive dipstick test for blood in the urine 


\begin{tabular}{|c|c|c|}
\hline \multicolumn{3}{|c|}{$\begin{array}{l}\text { Table } 1 \text { Age distribution of the study } \\
\text { patients }\end{array}$} \\
\hline Age (years) & No. ${ }^{a}$ & $\%$ \\
\hline $0-14$ & 2 & 13.9 \\
\hline $15-34$ & 48 & 60.8 \\
\hline $35-54$ & 10 & 12.7 \\
\hline$>55$ & 8 & 10.1 \\
\hline Unknown & 2 & 2.5 \\
\hline
\end{tabular}

${ }^{a}$ Data on age were missing for 9 patients.

in the group with ARF than in those without. The degree of reaction of the urine dipstick test was also significantly higher in this group.

When the patients were divided into 2 groups: low-risk (urine blood: negative, $1+$ and $2+$ ) and high-risk (urine blood: $3+$ and $4+$ ), the sensitivity and specificity of urine blood in high-risk patients for prediction of occurrence of ARF was 100\% (95\% CI: 67\%-100\%) and $74 \%$ (95\% CI: 63\%-83\%) respectively. Positive predictive value and negative predictive values were 30\% (95\% CI: $16 \%-49 \%)$ and $100 \%$ (95\% CI: 93\%-100\%) respectively. The accuracy of the dipstick test in prediction of ARF was $77 \%$ (95\% CI: 68\%-83\%). The AUC was 0.90 (95\% CI: 0.79-0.96).

Mean serum CPK levels were 13225 (SD 11554 ) IU/L (range 2430-34 $230 \mathrm{IU} / \mathrm{L})$ and 1882 (SD 2023) IU/L (range 39-11 424 IU/L) in patients with and without ARF respectively $(P<0.001)$. When the patients were divided into low-risk (CPK level $\leq 2259 \mathrm{IU} / \mathrm{L})$ and high-risk (CPK level $>2259$ IU/L) groups, the sensitivity and specificity of CPK in high-risk patients for detection of ARF was 100\% (95\% CI: 64\%-100\%) and 68\% (95\% CI: 54\%-79\%) respectively. Positive predictive value and negative predictive values were $23 \%$ (95\% CI: $10 \%-45 \%$ ) and 100\% (95\% CI: 90\%-100\%) respectively. The accuracy of serum CPK in prediction of ARF was $71 \%$ (95\% CI: 60\%-80\%). AUC was 0.890 (95\% CI: 0.77-0.95).

Comparison of the AUCs of serum CPK level and urine blood by dipstick did not show a significant difference $(P$ $=0.929$ ).

\section{Discussion}

The results of this study showed that the dipstick urine test is a highly sensitive and easyscreening tool for identification of patients who are at risk of developing ARF due to rhabdomyolysis and may have a role in the early detection of patients at the site of an earthquake. Also comparison of the dipstick urine test with serum CPK level (gold standard) did not reveal any significant differences.

A positive urine myoglobin test provides supportive evidence of

Table 2 Urine dipstick results of patients with and without acute renal failure in the first 3 days after suffering trauma

\begin{tabular}{lccc} 
Variable & \multicolumn{2}{c}{ Acute renal failure } & $P$-value \\
& Yes $(\boldsymbol{n}=8)$ & No $(\boldsymbol{n}=71)$ & \\
Dipstick & 0 & 34 & $0.018^{\mathrm{a}}$ \\
$\quad$ Negative & 8 & 37 & \\
$\quad$ Positive & & & $0.024^{\mathrm{b}}$ \\
Intensity of positive samples & 0 & 34 & \\
0 & 0 & 9 & \\
$1+$ & 0 & 10 & \\
$2+$ & 7 & 13 & \\
$3+$ & 1 & 5 & \\
$4+$ & &
\end{tabular}

${ }^{a}$ Fisher exact test; ${ }^{b}$ Chi-squared test.

rhabdomyolysis [7] and some other studies have been done on patients with trauma. In a study of cases of traumatic rhabdomyolysis, Muckart et al. revealed that an initial venous bicarbonate concentration of $<17 \mathrm{mmol} / \mathrm{L}$ with myoglobinuria is highly sensitive for predicting ARF [17]. Spicer et al. in a study of patients with acute renal impairment due to immersion and near-drowning, found that a dipstick reaction on admission was significantly more common in patients with acute renal impairment [13]. Also Melli et al. in a review of 475 patients with rhabdomyolysis, showed that urine myoglobin detected by dipstick/ultrafiltration was positive in $19 \%$ [18]. However, other studies found a lack of adequate sensitivity [19].

As we wanted to assess the efficacy of dipstick urine test at the site of the earthquake, we did not exclude cases with haematuria; however, some investigators have emphasized that for clinical purposes, myoglobinuria is just demonstrated by a blood-positive dipstick when there is no haematuria or haemoglobinuria [20]. However, we had no patients with overt abdominalpelvic injuries and likely traumatic haematuria. Also we did not perform dipstick test in the first urine sample after catheterization.

The importance of early initiation of vigorous fluid resuscitation and other medical treatments in earthquake victims have been emphasized. In mass disasters, early treatment in the field should be focused on seriously injured persons who require immediate care [21]. To identify patients at risk of renal damage, the quickest and least expensive screening test for rhabdomyolysis is the serum CPK level [22]; however, it has to be performed in a hospital setting and with the lack of medical equipment and personnel in the field in an emergency, it is hard to use it as an effective diagnostic tool.

Increased muscle enzymes particularly $\mathrm{CPK}$ is a marker of muscle injury [23]. Reported thresholds ofCPK in the 


\begin{tabular}{|c|c|c|c|}
\hline \multirow{2}{*}{$\begin{array}{l}\text { Creatine phosphokinase } \\
\text { level (IU/L) }\end{array}$} & \multicolumn{2}{|c|}{ Acute renal failure } & \multirow[t]{2}{*}{ Total $(n=79)$} \\
\hline & Yes $(n=8)$ & No $(n=71)$ & \\
\hline$\leq 2259$ & 0 & 35 & 35 \\
\hline$>2259$ & 5 & 16 & 21 \\
\hline Total & 5 & 51 & 56 \\
\hline
\end{tabular}

$P=0.005$.

literature vary from 500 to $3000 \mathrm{IU} / \mathrm{L}$ [23]. In this study we found a serum CPK threshold of $>2259$ IU/L for prediction of ARF. Our results showed that the dipstick urine test and serum CPK level had the same sensitivity for prediction of ARF; however, the specificity of the dipstick urine test was slightly higher than for CPK. Considering the fact that our study did not find any significant differences between these 2 tests, dipstick urine test has a great advantage as it can be easily performed at the site of the injury.

Another important problem to be considered is the time between injury and appearance of sufficient amounts of myoglobin to be detected in the urine sample by dipstick. When urine myoglobin concentration is $<60000 \mu \mathrm{g} / \mathrm{L}$, utilization of conventional dipstick has the potential to misdiagnose patients with myoglobin concentrations associated with increased risk of subsequent renal dysfunction [24]. Then a normal urine dipstick test result does not rule out this condition [18].

There were important limitations in this study. First, we assessed dipstick results visually. To minimize the confounder effects of human error, it would be better to assess the dipsticks with an automated analyser. Furthermore, it was not possible to identify whether the positive dipstick test was caused by the presence of blood, myoglobin or both in urine. The presence of blood in urine causes significant false positive readings (both for visual and automated assessments), which has negative effects on the specificity and, in turn, on the accuracy of urinary dipstick in detection of myoglobinuria. To minimize this problem, we divided our patients into 2 groups of high- and low-risk for development of ARF according to the colour chart on the dipstick bottle. In addition, in some of our cases, there was a 36-hour gap between the injury and dipstick test. Thus, it is possible that the therapeutic efforts in this time interval influenced the final results. Finally the number of patients who suffered from ARF was small $(n=8)$ and so the results are preliminary. Therefore, the results need to be tested on other data sets before clinical application.

In conclusion, our results did not reveal significant differences between dipstick urine test and serum CPK in identifying patients who were at risk of ARF. However, in view of the high sensitivity of urine dipstick test and its ease of use in the field, we suggest that utilization of this test as an early screening tool in detection of victims prone to ARF may have benefits and facilitate triage of high-risk patients. Further studies are needed to evaluate the potential efficacy of dipstick urine test.

\section{References}

1. Emami MJ et al. Strategies in evaluation and management of Bam earthquake victims. Prehospital and Disaster Medicine, 2005, 20(5):327-330.

2. Ukai T. The great Hanshin-Awaji earthquake and the problems with emergency medical care. Renal Failure, 1997, 19(5):633645.

3. Malinoski DJ, et al. Crush injury and rhabdomyolysis. Critical Care Clinics, 2004, 20(1):171-192.

4. Bagley $\mathrm{WH}$ et al. Rhabdomyolysis. Internal and Emergency Medicine, 2007, 2(3):210-218.

5. Atef MR et al. Acute renal failure in earthquake victims in Iran: Epidemiology and management. Quarterly Journal of Medicine, 1994, 87(1):35-40.

6. Poels PJE et al. Rhabdomyolysis: a review of the literature. Clinical Neurology and Neurosurgery, 1993, 95(3):175-192.

7. Sauret JM et al. Rhabdomyolysis. American Family Physician, 2002, 65(5):907-912.

8. Lima RS et al. Acute kidney injury due to rhabdomyolysis. Saudi journal of kidney diseases and transplantation, 2008, 19(5):721-729.

9. Line RL et al. Acute exertional rhabdomyolysis. American Family Physician, 1995, 52(2):502-506.
10. Young SE et al. Is urine dipstick a reliable screening tool for rhabdomyolysis in the suspected heat injury patient? Annals of Emergency Medicine, 2006, 48(4 Suppl.):90.

11. Peebles J et al. Child physical abuse and rhabdomyolysis: case report and literature review. Pediatric Emergency Care, 2007, 23(7):474-477.

12. Os I et al. General convulsions and rhabdomyolysis. Case reports. Acta Neurologica Scandinavica, 1989, 79(3):246-248.

13. Spicer ST et al. Acute renal impairment after immersion and near-drowning. Journal of the American Society of Nephrology. 1999, 10(2):382-386.

14. Sinert R et al. Exercise-induced rhabdomyolysis. Annals of Emergency Medicine, 1994, 23(6):1301-1306.

15. Ward MM. Factors predictive of acute renal failure in rhabdomyolysis. Archives of Internal Medicine, 1988, 148(7):1553-1557.

16. Gunal $\mathrm{Al}$ et al. Early and vigorous fluid resuscitation prevents acute renal failure in the crush victims of catastrophic earthquakes. Journal of the American Society of Nephrology, 2004, 15(7):1862-1867.

17. Muckart DJJ et al. Prediction of acute renal failure following soft-tissue injury using the venous bicarbonate concentration. Journal of Trauma, 1992, 33(6):813-817. 
18. Melli $\mathrm{G}$ et al. Rhabdomyolysis: an evaluation of 475 hospitalized patients. Medicine (Baltimore), 2005, 84(6):377-385.

19. Gabow PA, et al. The spectrum of rhabdomyolysis. Medicine (Baltimore), 1982, 61(3):141-152.

20. Briner $\mathrm{V}$ et al. Die akute Rhabdomyolyse [Acute rhabdomyolysis]. Schweizerische Medizinische Wochenschrift, 1986, 116(7):198-208.

21. Pepe PE et al. Field management and critical care in mass disasters. Critical Care Clinics, 1991, 7(2):401-420.
22. Mote JD et al. Rhabdomyolysis and acute renal failure. Medicina Interna de Mexico, 2007, 23(1):47-58.

23. Sever MS et al. The Marmara earthquake: Admission laboratory features of patients with nephrological problems. Nephrology Dialysis Transplantation, 2002, 17(6):1025-1031.

24. Loun B et al. Ultrafiltration discrepancies in recovery of myoglobin from urine. Clinical Chemistry, 1996, 42(6 Suppl.):965969.

\section{Diagnostics and Laboratory Technology}

The goal of the World Health Organization's Diagnostics and Laboratory Technology team is to promote and facilitate access to safe, reliable and appropriate diagnostic technologies and laboratory services in an equitable manner through:

- Prequalification of diagnostics for high burden diseases;

- Capacity building of national regulatory authorities and national reference laboratories;

- Facilitation of procurement of affordable and appropriate diagnostics;

- Policy, guidance and advocacy to Member States;

- Provision of quality assurance programmes to countries;

- Training and technical support including country projects.

Further information about the work of WHO in Diagnostics and Laboratory Technology is available at: http:/ wwww. who.int/topics/diagnostic_techniques_procedures/en/ 